\title{
Using GIS Techniques for Modeling Noise Propagation from Mechanized Harvesting Equipment*
}

\author{
Abdullah E. Akay ${ }^{* 1}$ (D), H. Hulusi Acar ${ }^{2}$ \\ ${ }^{1}$ Bursa Technical University, Faculty of Forestry, 16310 Bursa, Turkey \\ ${ }^{2}$ İstanbul Yeni Yüzyıl University, Zeytinburnu, İstanbul, Turkey
}

\begin{abstract}
The noise is a kind of environmental pollutions that affects human health and decreases performance of people, education, and home life. Harvesting activities in forestry are one of working environments where noise effect is very intense. Noise is an element of environmental pollution that is effective on human health and needs to be controlled. To evaluate the noise effect, maps of noise propagation are used. The noise map is defined as numerical model of noise sources. The changes in sound level determined by measurements in certain points are shown in noise map. Noise maps are used in calculation of average sound level if it is within acceptable limits and in determination of risky areas where employees are adversely effected. Computer-aided systems have been used in modeling noise propagation in recent years. SPreAD-GIS is free program developed to estimate acoustic effects of anthropogenic noise propagation and adapted to ArcGIS software. In this study, it was aimed to introduce SPreAD-GIS program that can be used to model noise propagation caused by mechanized harvesting equipment. In addition, main factors affecting noise propagation in forest (elevation, land use type, temperature, humidity, wind direction and intensity, climate and weather conditions) were evaluated.
\end{abstract}

Keywords: Forest harvesting, Noise propagation, Noise map, GIS

\section{Introduction}

Technological innovations, industrial developments and urbanization have made numerous important contributions and conveniences to human life, but also brought some negative effects on natural resources and ecosystems. Environmental pollution such as air pollution, water pollution, soil pollution and noise pollution are the most important problems. Anthropogenic noise pollution, which is an important element of environmental pollution and an increasing problem in our lives day by day, consists of vehicles used in land, sea and air traffic, construction equipment, electrical machinery.

The number of vibrations of sound per unit time is the frequency of the sound and its unit is hertz $(\mathrm{Hz})$. The hearing range of the human ear is between 20 and 20000 $\mathrm{Hz}$, and the most comfortable sound frequencies are between 200 and $4000 \mathrm{~Hz}$ (Y1lmaz, 2007). The factors affecting the propagation of sound are distance to the sound source, the absorbance of the sound environment, meteorological parameters (temperature, wind, air movements), the absorption of the ground, the presence of forest and woodland areas and natural and/or artificial obstacles (Aydın, 2015).

The A-weighted sound pressure level $(\mathrm{dBA})$ is the sound pressure unit in which the medium and high frequencies to which the human ear is sensitive are particularly emphasized. A-weighted sound levels are the most commonly used in noise control studies. Unwanted and disturbing sounds are called noise. In other words, noise is a collection of variable, high-pressure and complex sounds that have multiple frequency components that disturb our ears (Maraş et al., 2011).

Noise affecting human health physiologically, physically and psychologically is an environmental pollution that reduces the performance of people in work environment, education and home life. Scientific studies conducted in this area show that more than $20 \%$ of the world's population is exposed to above-normal noise levels and approximately $60 \%$ of the European population is exposed to high noise levels throughout the day (Rivas et al., 2003). Table 1 shows the negative effects of noise levels on people. 
Table 1. The negative effects of noise levels on people (Kurra, 1991)

\begin{tabular}{|c|c|c|}
\hline Degree & Value dBA & Effects \\
\hline 1 & $30-65$ & Discomfort, anger, sleep and attention disorder \\
\hline 2 & $65-90$ & $\begin{array}{l}\text { Increase of blood pressure, the acceleration of the } \\
\text { heartbeat and respiration }\end{array}$ \\
\hline 3 & $90-120$ & Headache \\
\hline 4 & $120-140$ & Permanent damage to the inner ear, balance disorder \\
\hline 5 & $>140$ & Severe brain damage \\
\hline
\end{tabular}

\section{Noise Effect in Forest Operations}

Production in forestry is one of the working environments where the noise effect can be very intense. Depending on the difficulty of the work and the type of equipment used, the effects of noise to forest workers and operators vary (Neitzel and Yost, 2001; Serin and Akay, 2010). The most commonly used equipment in forestry studies in Turkey is the chainsaw used in the cutting of trees, delimbing and bucking in the production of forest products. Studies have shown that the chainsaw is one of the most critical equipment in terms of noise level (Cavalli et al., 2004; Potocnik and Poje, 2010).

In a study conducted by Serin and Akay (2008), the noise level caused by the chainsaw was analyzed by making close and distant measurements $(15-20 \mathrm{~m})$. According to the results, the average noise level was measured as $83.19 \mathrm{dBA}$ in close measurements and 73.91 dBA in remote measurements. The maximum noise level (93.60 dBA) was obtained at close measurements. Taş et al. (2018) measured the average noise level as $80.18 \mathrm{dBA}$ in a study in which the effect of the chainsaw on the operator was investigated. The maximum noise level (100.77 dBA) during the measurements was measured at tree cutting.

Studies on the effects of noise level have shown that noise level of $80 \mathrm{dBA}$ and lower may not cause significant problems on worker health and the effect of noise can be prevented by using personal protective equipment (Güvercin and Aybek, 2003). On the other hand, $85 \mathrm{dBA}$ noise level is defined as the warning limit, while $90 \mathrm{dBA}$ and above is defined as the hazard limit containing risk. Accordingly, 85-115 dBA noise level leads to physiological and psychological health problems, while $115 \mathrm{dBA}$ or higher noise level can cause permanent hearing loss problems (Polat and Kirıkkaya, 2004). Working hours should be determined according to the noise level in order to protect workers' health from the negative effects of high noise level.

The noise generated during the use of chainsaws adversely affects wildlife in large areas as well as on the chainsaw operator and forest workers working in the environment. High noise levels cause cycle change and deterioration of animal life (Shannon et al., 2016). Natural animal cycles such as hunting, sheltering, breeding habits and migration routes change over time due to noise. The increase in noise level causes significant problems especially on bird species and negatively affects the hatching success during the reproduction period (Francis et al., 2009; Kleist et al., 2018). In studies examining the effects of noise on birds, noise levels above $45 \mathrm{dBA}$ have been reported to affect reproduction, stress hormone levels and species richness in birds (Shannon et al., 2016). In addition, the noise originating from the noise source and the regions where the natural noise difference in the environment increases to $20 \mathrm{dBA}$ and above are defined as critical areas for bird species (Proto et al., 2016). Delaney et al. (1999) in a study investigating the response of owls to noise, motor saw noise compared to helicopter noise, reported that owls are more disturbed than motor saw noise.

\section{Modeling of Noise Propagation}

Noise, like all other environmental pollution elements, is an environmental pollution element that has an impact on human health and needs to be controlled. Noise maps showing noise propagation are used to evaluate and control the noise effect. Noise map is defined as a numerical model of noise sources (Probst and Huber, 2003). Noise maps are used to calculate average sound levels, determine whether sound levels are within acceptable limits and identify risky areas where employees are adversely affected (Aydın, 2015). In addition, knowledge of noise sources and noise levels in an environment provides important information for determining the effects of noise pollution on different species and ecosystems (Keyel et al., 2017).

There have been studies on mapping of the noise regime in various regions of the world (Abrakitov, 2010; Barber et al., 2011; Reed et al., 2012; Mennitt et al., 2014; Grade and Sieving, 2016). In recent years, computer aided systems have been used effectively in modeling noise propagation. CadnaA is a software developed for the calculation and assessment of environmental noise. CadnaA software, which can evaluate the noise produced by industry, road and railway or noise from urban areas, can work integrated with GIS (Reed et al., 2009). LimA is a software package developed to assess noise emission in areas such as environmental planning, urban planning and protection of quiet areas (Martínez and Recuero, 2007). In the calculation of the noise level, meteorological parameters, the sound reduction effect of the land, the direction of the sound source and the contribution of each sound source are taken into consideration. LimA software can also be integrated with GIS. SoundPLAN, another noise modeling software, was developed for the estimation, evaluation and mapping of environmental 
noise. SoundPLAN, which is especially used in construction and new road planning projects, takes many parameters into account in determining the noise level. These parameters are; noise sources, traffic data, traffic flow, percentage of heavy vehicles, topography, building layouts, barriers and other design elements that may affect the spread of external noise (Italo et al., 2011).

SPreAD-GIS (System for the Prediction of Acoustic Detectability) is a free software developed to predict the acoustic effects of anthropogenic noise emission. SPreAD-GIS has been adapted to the ArcGIS software environment using ModelBuilder and Python algorithms. SPreAD-GIS is designed to model how noise is propagated in forests and other natural ecosystems. In the calculation of noise emission, wind and atmospheric effects, soil and vegetation effects and sound source characteristics are evaluated. Unlike other commercial software that measures a single sound level (A-weighted sound level) whose frequency spectrum is set to the human ear, the SPreAD-GIS software considers the diffusion of different frequencies in space during the calculation process. This is particularly important to predict the effects of noise on wildlife as different species are affected by noise at different frequencies (Reed et al., 2009).

\subsection{Noise Analysis}

The noise level caused by the forestry machine should be recorded at 1-second intervals using the Class 1 noise meter. When measuring the noise level to which the operator is exposed, the noise meter shall be located as close as possible to the operator's ears. During noise measurements, it shall be ensured that there are no other sources of noise in addition to the machine noise in the environment.

\subsection{SPreAD-GIS Noise Propagation Model}

The noise propagation map of the work area can be developed with the help of SPreAD-GIS in order to reveal potential noise effects on the operator, other workers in the production area and bird species during the production works by using the noise values derived from the machine measured by the noise analysis. Using SPreAD-GIS, noise from a specific point, line or polygon can be calculated for the $1 / 3$ octave frequency band and a map of noise propagation in all directions can be generated. The SPreAD-GIS installed as an extension to the ArcGIS program takes six emission factors into account to calculate the spatial propagation of noise. Figure 1-6 are sample maps showing the effect of these factors in the SPreAD-GIS environment (Reed et al., 2009).

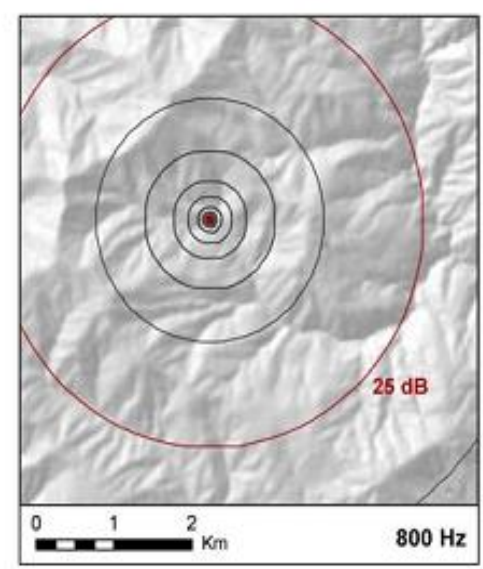

Figure 1. Global spread loss

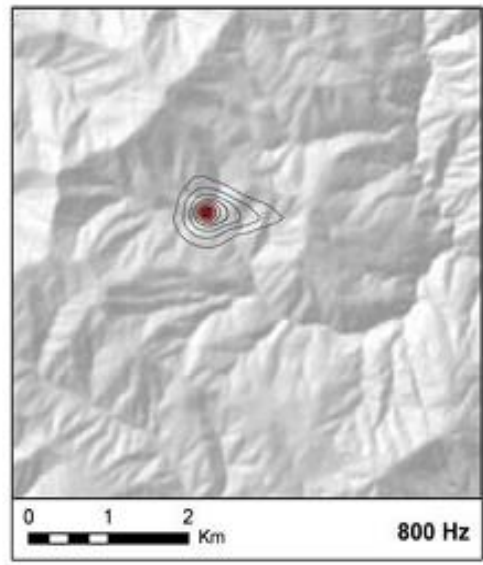

Figure 4. Loss caused by wind

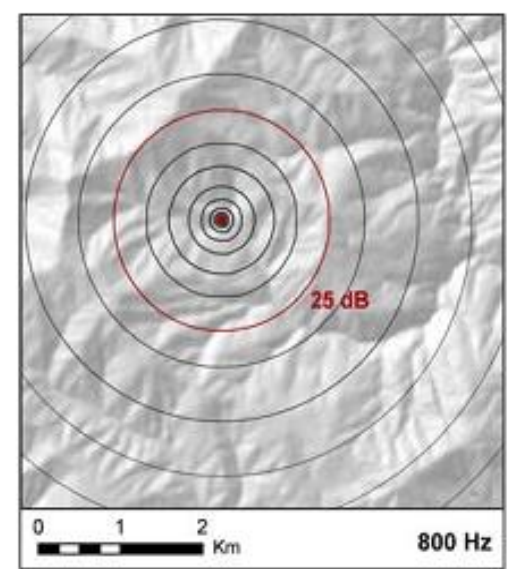

Figure 2. Loss of atmospheric absorption

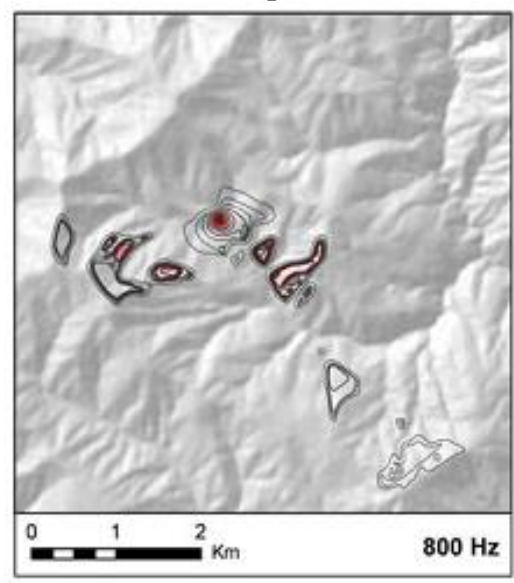

Figure 5. Loss due to land structure

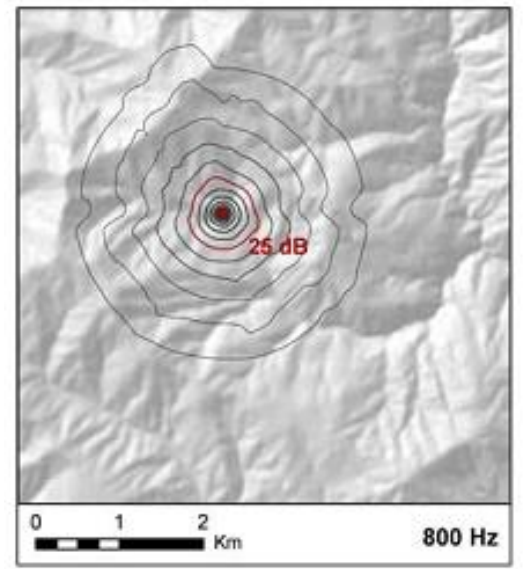

Figure 3. Land use type and vegetation loss

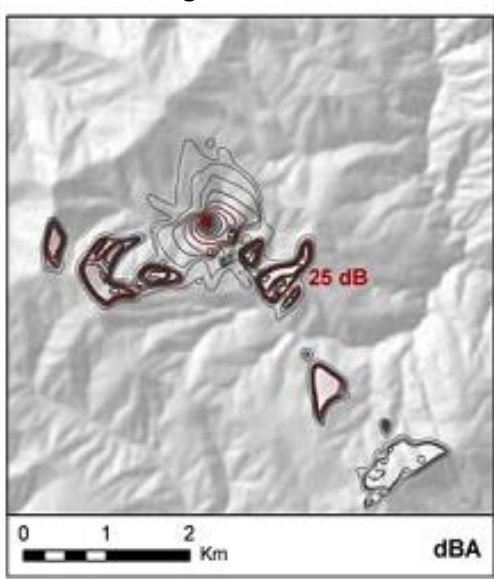

Figure 6. Excessive noise propagation 
The spherical propagation loss is calculated based on the distance from the noise source (Figure 1). The atmospheric absorption loss seen in Figure 2 is calculated as a function of air temperature, relative humidity and altitude. When the temperature rises with height, sound waves are refracted downward and good audibility is achieved over long distances (Hannah, 2006). Humidity also effects sound propagation, as it is higher when there is propagation of high-frequency $(>1000 \mathrm{~Hz}$ ) (Liptai et al., 2015). Land use type and vegetation losses are calculated according to the values absorbed on the ground and scattered according to land use type (coniferous, deciduous, meadow, settlement etc.) (Figure 3). The windinduced loss shown in Figure 4 is calculated according to the prevailing wind direction, wind speed and seasonal conditions. Losses due to land structure are calculated according to the decrease in noise level due to the barrier effect of hills or ridges in the field (Figure 5). Finally, excessive noise emission is calculated based on the difference between the noise emitted from the measured source and the ambient noise (Figure 6). Thus, it can be determined that the noise emitted from the source can be heard by exceeding the ambient noise and adversely affecting the wildlife in environment (Reed et al., 2009).

SPreAD-GIS allows the modeling of noise propagation for different $1 / 3$ octave frequency bands $(400$, $500,630,800,1000,1250,1600,2000 \mathrm{~Hz}$ ) from the point sources, taking into account different point noise sources. Thus, noise levels from different machines operating at the same time can be determined and maps representing excessive noise propagation can be produced.

\subsection{Database Development}

Before running SPreAD-GIS, the data sets required for the model should be provided and some parameters must be determined by field measurements. The data in the database include the location of noise sources, characteristics of noise sources, coverage of the model, Digital Terrain Model (DTM), land use type map, climate parameters and natural noise level in the environment.

\subsubsection{Location of Noise Sources}

The noise source file can be developed to represent the locations in the SPreAD-GIS database where noise is propagated within the workspace. The working area can be divided into grids. The center point of the grid are recorded in the noise source file in the SPreAD-GIS database as the noise source location. Considering that several operators work simultaneously, noise propagation calculations should be made by taking adjacent grids into account at a time. SPreAD-GIS produces the noise emission map in raster data format with a resolution of 30 $\mathrm{m}$, and the final noise emission map considers the value of the combination.

\subsubsection{Properties of Noise Sources}

Various characteristics of the noise source should be defined. SPreAD-GIS allows the user to select from the noise level data of the engines of different machines installed in the database (Martin et al., 2005). On the other hand, when users want to use their own data or want to develop a noise propagation model for machines that are not in the database, the data of some characteristics of the noise source (1/3 octave frequency band, noise level, distance between noise meter and noise source) must be defined in the system. The noise level values arising from the machine for 500,1000 and $2000 \mathrm{~Hz}$ of $1 / 3$ octave frequency bands should be considered. The reason why these three bands are selected is that many bird species along with humans are sensitive to noise in the 500, 1000 and $2000 \mathrm{~Hz}$ frequency range (Delaney et al., 1999). Another characteristic of the noise source is the distance to the noise source during measurements. In SPreAD-GIS environment, the noise source distance can be defined by the user to the system. In this study, since the noise meter is planned to be placed as close to the operator's ears as possible, the distance from the noise source will be $0.30 \mathrm{~m}$.

\subsubsection{Model Coverage}

In SPreAD-GIS, the coverage area of the model represents the spatial coverage determined for noise propagation analysis. The pattern coverage area is generally in the form of a polygon, but can be of any size or shape. As the coverage area increases, processing time increases in SPreAD-GIS (Reed et al., 2009).

\subsubsection{Digital Terrain Model}

In order to evaluate the effect of land structure on noise propagation during the process of the model, the Digital Terrain Model (DTM) of the study area should be prepared. The DTM should cover the coverage area expressed in the above section and the cell size should have a resolution of $30 \mathrm{~m}$. Within the scope of this study, DTM can be developed by using contour map.

\subsubsection{Land Use Type Map}

In order to evaluate the impact of the existing land use type on noise propagation in SPreAD-GIS model, land use type data layer $(30 \mathrm{~m})$ should be prepared. In Turkey, stand type map can be obtained from Forest Enterprise Directorate to produce land use type data layer. Each land use type in this data layer can then be converted to one of the land use types defined in the SPreAD-GIS environment (Table 2).

Table 2. Land use types defined in SPreAD-GIS

\begin{tabular}{lc}
\hline Land Use Types & Symbol \\
\hline Coniferous & CON \\
Broadleaves & HWD \\
Range & HEB \\
Shrubs & SHB \\
Bareland & BAR \\
Water & WAT \\
Settlements & URB \\
\hline
\end{tabular}




\subsubsection{Climate Parameters}

In the modeling of noise propagation using SPreADGIS, it is necessary to provide data for some climatic parameters for the day and season when land measurements are made. These climate parameters; temperature $\left({ }^{\circ} \mathrm{C}\right)$, relative humidity $(\%)$, dominant wind direction $\left({ }^{\circ}\right)$, wind speed $(\mathrm{km} / \mathrm{h})$ and seasonal conditions. The model also has a list to define the seasonal conditions, from which the user can select the seasonal condition that best represents the status of the measured time. Some of the seasonal conditions listed are: "clear, calm summer day, "clear, calm winter day", "clear, windy summer day ", "clear, windy winter day", " cloudy and calm", "cloudy and windy". In the field, ambient temperature, relative humidity, wind speed and direction can be measured using a portable weather station. Seasonal conditions should be determined and recorded at the time of measurement in the field.

\subsubsection{Natural Noise Level in the Environment}

In the final stage, the noise conditions in the working area are to be defined and thus the areas in the model where the noise from the machine can be heard at different frequencies can be determined. In this context, ambient noise level values suggested by the system can be entered or used in special values measured by the user. If userspecific ambient noise measurements are preferred, it is necessary to measure the ambient noise level for all of the different $1 / 3$ octave frequency bands evaluated under SPreAD-GIS or for target frequency bands. To determine the natural noise level in the environment, three repetitive noise measurements can be performed for each land use type for a period of five minutes during which the machine is not operated and no noise source is active in the environment.

\subsection{Generation of Noise Propagation Maps}

In SPreAD-GIS environment, a spatial propagation model of anthropogenic noise can be developed by considering six noise emission factors and three frequency bands $(500,1000,2000 \mathrm{~Hz})$. As model outputs, maps showing noise propagation in raster data format should be produced. Noise emission maps can be developed at $5 \mathrm{dBA}$ intervals. In the final noise emission maps, the combination giving the highest pixel value among combinations for each pixel should be considered. By calculating the projected noise emission around the noise source, the noise exposure of the personnel working around the noise source can be determined. Figure 7 shows an exemplary noise emission map developed using SPreAD-GIS (Reed et al., 2009).

By calculating the difference between the noise from the noise source and the natural noise levels in the environment, the areas where the noise emitted from the source is likely to be heard and the areas where the bird species in the area can be affected can be determined. The noise propagation map to be developed and the map of the bird breeding area of the site should be overlapped and the effects of the noise generated by the machine on the bird species can be evaluated. Areas where noise levels above $45 \mathrm{dBA}$ and above determined to affect reproduction, stress hormone level and species richness in bird species will be determined. In addition, the noise originating from the noise source and the regions where the natural noise difference in the environment exceeds $20 \mathrm{dBA}$ and critical for bird species should be determined (Reed et al., 2009).

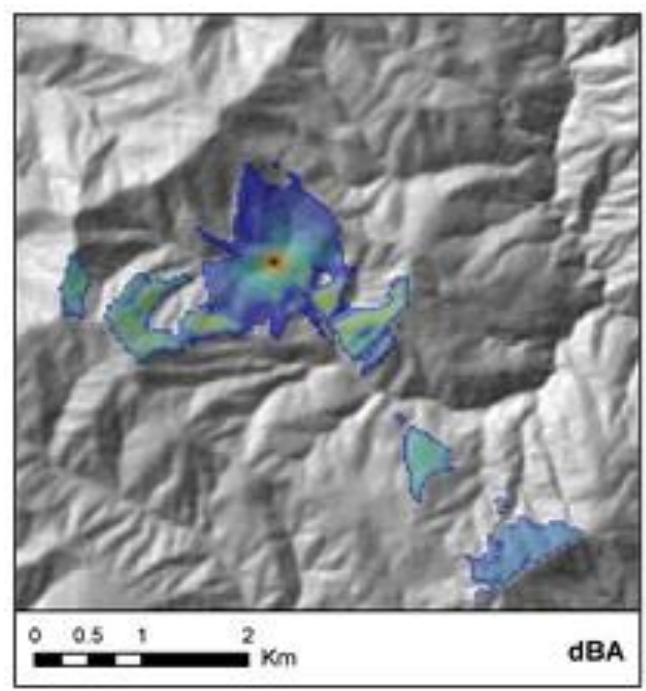

Figure 7. Propagation model of noise from noise source

\section{Conclusions}

In this study, the map of the noise caused by the forestry machine on the operators and other forest workers was evaluated. The generation of noise propagation map by using SPreAD-GIS software was introduced based on the noise effect on the forest workers and bird species. Using the noise emission map, the effects of topographic, ecological and climatic factors on the noise emission from the machine can be evaluated and ergonomic methods and technical solutions can be proposed to minimize the effects of noise on the operator and other employees. Some of the main measures to be taken:

- Ear protection equipment should be used to reduce the impact of noise on operators and workers.

- Use of ear protection equipment should be encouraged and inspected if necessary.

- In order to prevent permanent damages on the operators, operations should be interrupted during the work hours.

- Maintenance of the machines should be done properly and with adequate frequency.

- Seminars and on-the-job trainings should be given to operators about potential damages of noise and how to minimize their effects.

- The operators should go for health checks to prevent temporary damages to become permanent ones.

In addition, the possible effects of anthropogenic noise propagation on wildlife species (birds) can be investigated using the noise propagation map. If the noise level caused 
by the machine exceeds the critical values of the bird species living and breeding areas in the field, operational measures to be taken to minimize noise damage (production schedule planning, appropriate machine selection, appropriate working hours, working methods, etc.) should be implemented.

\section{Acknowledgements}

This study is funded by The Scientific and Technological Research Council of Turkey (TUBITAK) with the project number 1190736 .

\section{References}

Aydın, B. 2015. Noise mapping on an university campus area: case study for Istanbul Technical University Ayazaga Campus. Master Thesis, İTÜ FBE, İstanbul. $98 \mathrm{p}$.

Cavalli, R., Miola, P., Sartori, L. 2004. Diffusione del rumore prodotto dalla motosega in boschi con differenti forme di governo. L'Italia Forestale $e$ Montana, 59(3): 375-390.

Barber, J.R., Burdett, C.L., Reed, S.E., Warner, K.A., Formichella, C., Crooks, K.R., Theobald, D.M., Fristrup, K.M., 2011. Anthropogenic noise exposure in protected natural areas: estimating the scale of ecological consequences. Landsc. Ecol. 26: 12811295.

Delaney, D.K., Grubb, T.G., Beier, P., Pater, L.L., Hildegard Reiser, M. 1999. Effects of helicopter noise on Mexican spotted owls. Journal of Wildlife Management, 63(1): 60-76.

Francis, C.D., Ortega, C.P., Cruz, A. 2009. Noise pollution changes avian communities and species interactions. Current Biology, 19: 1415-1419.

Grade, A.M., Sieving, K.E., 2016. When the birds go unheard: highway noise disrupts information transfer between bird species. Biol. Lett. 12, 20160113.

Güvercin, Ö., Aybek, A. 2003. Noise Problem In Stone Pulverizing and Sieving Plants. KSU Journal of Science and Engineering. 6(2): 101-107.

Italo, C., Guedes, M., Bertoli, S.R., Zannin, P.H.T. 2011. Influence of urban shapes on environmental noise: A case study in Aracaju, Brazil, Science of the Total Environment, 412-413: 66-76.

Keyel, A.C., Reed, S.E., McKenna, M.F., Wittemyer, G. 2017. Modeling anthropogenic noise propagation using the Sound Mapping Tools ArcGIS toolbox. Environmental Modelling \& Software, 97:56-60.

Kleist, N.J., Guralnick, R.P., Cruz, A., Lowry, C.A., Francis, C.D. 2018. Chronic anthropogenic noise disrupts glucocorticoid signaling and has multiple effects on fitness in an avian community. PNAS, 115(4): 648-657.

Kurra, S. 1991. Noise, Turkey's Environmental Problems, Turkey Environment Foundation Publications, Ankara. pp. 447-484.
Liptai, P., Badida, M., Katarína, L., 2015. Influence of Atmospheric Conditions on Sound Propagation Mathematical Modeling, Óbuda University eBulletin, 5(1): 2015-127.

Maraş, E.E., Maraş, H.H., Maraş, S.S., Alkış, Z. 2011. Analysis of the Prediction Method Used in Environmental Noise Mapping from GIS Data. Mapping Journal. 145: 52-60.

Martin, S.A., Leung, A., Pallini, P. 2005. California offhighway vehicle noise study. Wyle Laboratories, Inc., El Segundo, CA.

Martínez, E., Recuero, M. 2007. Comparison of Computer Software for External Noise Prediction", $19^{\text {th }}$ International Congress on Acoustics, 2-7 September, Madrid, Spain.

Mennitt, D., Sherrill, K., Fristrup, K., 2014. A geospatial model of ambient sound pressure levels in the contiguous United States. J. Acoust. Soc. Am. 135: 2746-2764.

Neitzel, R., Yost, M. 2001. Task-based Assessment of Occupational Vibration and Noise Exposures in Forestry Workers. The International Mountain Logging and 11th Pacific Northwest Skyline Symposium, 10-12 December, Seattle, Washington, USA. pp: 21-27.

Polat, S., Kırıkkaya, E.B. 2004. Effects of Noise on Education and Teaching. XIII. National Educational Sciences Congress, 6-9 July, İnönü University, Faculty of Education, Malatya, Turkey.

Potocnik, I., Poje, A. 2010. Noise pollution in forest environment due to forest operations. Croatian Journal of Forest Engineering. 32(2): 137-148.

Probst, W., Huber, B. 2003. The Sound Power Level of Cities, Sound and Vibration, 37(5): 14-17.

Proto, A.R., Grigolato, S., Mologni, O., Macrì, G., Zimbalatti, G., Cavalli, R. 2016. Modelling noise propagation generated by forest operations: a case study in Southern Italy. Procedia -Social and Behavioral Sciences. 223: 841- 848.

Reed, S.E., Mann, J.P., Boggs, J.L. 2009. SPreAD-GIS: an ArcGIS toolbox for modeling the propagation of engine noise in a wildland setting. Version 1.2. The Wilderness Society, San Francisco, CA. 32 p.

Reed, S.E., Boggs, J.L., Mann, J.P., 2012. A GIS tool for modeling anthropogenic noise propagation in natural ecosystems. Environ. Model. Softw. 37: 1-5.

Rivas, S., Hernandz, R., Cueto, J.L. 2003. Evaluation and Prediction of Noise Pollution Levels in Urban Areas of Cdiz (Spain). The Journal of the Acoustical Society of America, 114: 2439-2439.

Serin, H., Akay, A.E. 2008. Analysis of Noise Level During Logging. XIV. National Ergonomics Congress 30 October-1 November, Trabzon, Turkey. pp. 412-416.

Serin, H., Akay, A. E. 2010. Noise Level Analysis of a Bulldozer Used in Constructing a Forest Road in 
Mediterranean Region of Turkey, African Journal of Agricultural Research, 5(19): 2624-2628.

Shannon, G., McKenna, M.F., Angeloni, L.M., Crooks, K.R., Fristrup, K.M., Brown, E., Warner, K.A., Nelson, M.D., White, C., Briggs, J., McFarland, S., Wittemyer, G. 2016. A synthesis of two decades of research documenting the effects of noise on wildlife. Biol. Rev., 91: 982-1005.
Taş, İ., Akay, A.E., Büyüksakallı, H. 2018. Analysis of Noise Level Caused by a Chainsaw During Tree Felling Operations. INES Congress, 30 Octorber-3 November. Alanya, Turkey.

Y1lmaz, S. 2007. Environmental and Building Acoustics Handbook for Architects and Engineers, Birsen Publications. $511 \mathrm{p}$. 